\title{
Editorial
}

\section{Preventing neonatal herpes?}

In the United Kingdom no national management policies exist for women with genital herpes during pregnancy. Some women are subjected to frequent genital examinations and multiple viral cultures, some have unnecessary caesarean sections, and others receive no additional monitoring. The number of cases of herpes simplex infection seen in genitourinary clinics in England and Wales more than doubled between 1978 and $1988 .{ }^{1}$ A recently established voluntary notification system within the United Kingdom shows an incidence of neonatal herpes of less than 3 per 100,000 live births. ${ }^{2}$ Insufficient data exist to establish a trend but this incidence is probably an underestimate because notification is voluntary; many mothers are both asymptomatic at the time of delivery and have no history of genital herpes; ${ }^{3}$ the condition may develop after infants have left hospital, making diagnosis less likely; and classical lesions may never develop. Early treatment of neonates with anti-virals has not been shown to eliminate the considerable risk of death or serious sequelae of this condition ${ }^{4}$ so the reasons for the failure of current policies must be examined and rational alternatives proposed.

Whilst most infants with neonatal herpes are thought to be infected during labour, transplacental infection does rarely occur. Infection from nongenital maternal sources, for example, the breast, ${ }^{5}$ has been documented, as has infection from relatives and medical or paramedical personnel. ${ }^{3}$ The role of invasive monitoring techniques such as scalp electrodes in facilitating transmission is unknown. Clear advice to hospital personnel and pregnant women about the risks to neonates from herpetic lesions might prevent some such cases.

Primary maternal genital herpes during pregnancy has been shown to pose a high risk of transmission to the neonate as large amounts of virus are present, the cervix is frequently affected, lesions are larger and present for longer and maternal antibody levels may be lower than in recurrent disease. ${ }^{6}$ Recurrent genital herpes presents a lower risk to the neonate but factors which probably affect transmission including duration of labour, duration of membrane rupture, site of herpes lesions, amount of virus present, maternal antibody levels and fetal instrumentation during labour have rarely been considered in studies of women with recurrent disease.

Recent prospective studies have described seven women with primary herpes simplex during the third trimester or at term. Of the seven babies, three had neonatal herpes infection and two others had serious perinatal morbidity with no known cause. ${ }^{78}$ Four prospective studies identified women with recurrent herpes who were shedding virus at term and observed the outcome for the infants. These studies showed transmission rates of between $0 \%$ and $4.3 \%$. However, a number of the recurrences were asymptomatic, and where lesions were present the site was seldom reported. ${ }^{7-11}$

Retrospective studies have identified that between $15 \%$ and $19 \%$ of neonates with herpes infection are born to mothers with recurrent herpes, ${ }^{3-12}$ but since maternal history alone is an insensitive marker of prior herpes infection and serological assessment is not possible in retrospective studies, these results must be interpreted with caution. Large scale prospective studies of pregnant women and the outcomes of their pregnancies with recording of past history of herpes infection, serological evidence of herpes infection and carefully recorded details of labour are needed to help determine the true risks to neonates.

Present screening, where it exists at all, usually depends upon maternal history of past herpes simplex virus (HSV) infection (a poor marker of prior exposure) and repeated viral cultures near to term, a poor predictor of viral shedding during labour. ${ }^{9}$

Alternative strategies might include serological detection of women with HSV infection, using the new type specific serological assays. ${ }^{1314}$ This would enable the clinician to detect women with previous exposure to HSV 2 and therefore at risk of recurrent infection, as well as those who seroconvert during pregnancy. Counselling, recognition of recurrences and early presentation in labour could prove helpful.

The use of anti-virals during pregnancy requires assessment by controlled clinical trials. Whilst the safety of acyclovir during pregnancy has not been established there have been no reports of any adverse effect on pregnancy outcome where it has been given inadvertently. ${ }^{15}$ Acyclovir suppression has been proved to decrease the frequency of herpes recurrence. ${ }^{16-20}$ An option for the future might therefore be to offer all pregnant women identified as having recurrent genital herpes or with serological evidence of past HSV 2 infection suppressive acyclovir treatment from, for example, 36 weeks gestation until 
term. This has the advantage of avoiding multiple examinations and viral cultures, would eliminate the need for caesarian section and would also reduce haematogenous spread. The disadvantages are the dependence upon patient compliance and that women with genital HSV 1 would not be identified.

A recent report of the use of acyclovir in late pregnancy was non-blinded and apparently non-randomised and has therefore not provided satisfactory evidence of the efficacy of this approach. ${ }^{21}$

Without large scale carefully monitored trials of women with and without histories of genital herpes, with recording of greater detail about the nature of any recurrence and the characteristics of labour, the question of the best method of reducing neonatal herpes will remain unanswered and serious morbidity and mortality will continue.

D E MERCEY

Department of Genitourinary Medicine, The Middlesex Hospital A MINDEL

Academic Department of Genitourinary Medicine, University College and Middlesex School of Medicine, London W1N 8AA, UK

Address correspondence to Dr D E Mercey.

1 New cases seen at NHS Genito-Urinary Medicine Clinics in England. 1988 Annual and December Quarter Figures. Summary Information from form KC60. London: Department of Health, 1990.

2 British Paediatric Surveillance Unit (1988) Third Annual Report.

3 Yeager AS, Arvin AM. Reasons for the absence of a history of recurrent genital infections in mothers of neonates infected with herpes simplex virus. Pediatrics 1984;73:188.

4 Whitley RJ, Arvin A, Corey L, et al. Vidarabine versus acyclovir therapy of neonatal herpes simplex virus HSV infection (abstr). Pediatr Res 1986;20:323.

5 Whitley RJ, Nahmias AJ, Visintine AM, Fleming CL, Alford CA. The natural history of herpes simplex virus infection of mother and newborn. Paediatrics 1980;66:489.

6 Corey L, Adams HG, Brown ZA, Holmes KK. Genital herpes simplex virus infections: clinical manifestations, course, and complications. Ann Intern Med 1983;98:958-72.
7 Prober CG, Hensleigh PA, Boucher FD, Yasukawa LL, Au DS, Arvin AM. Use of routine viral cultures at delivery to identify neonates exposed to herpes simplex virus. $N$ Engl J Med 1988;318:887.

8 Brown ZA, Vontver LA, Benedetti J. Effects on infants of a first episode of genital herpes during pregnancy. $N$ Engl J Med 1987;317:1246

9 Arvin AM, Hensleigh PA, Prober CG, et al. Failure of antepartum maternal cultures to predict the infant's risk of exposure to herpes simplex virus at delivery. $N$ Engl J Med 1986;315:796.

10 Prober CG, Sullender WM, Yasukawa LL, Au DS, Yeager AS, Arvin AM. Low risk of herpes simplex virus in neonates exposed to the virus at the time of vaginal delivery to mothers with recurrent genital herpes simplex virus infections. $N$ Engl J Med 1987;316:240.

11 Nahmias AJ, Josey WE, Naib ZM, Freeman MG, Fernandel RJ, Wheeler JH. Perinatal risk associated with maternal genital herpes simplex virus infection. Am J Obstet Gynecol 1971; 110:825.

12 Sullivan-Bolyai H, Hull HF, Wilson C, Corey L. Neonatal herpes simplex infection in King County, Washington. $J A M A$ 1983;250:3059.

13 Lee FK, Coleman RM, Pereiral L, Bailey PD, Tatsuno M, Nahmias AJ. Detection of herpes simplex virus type 2 . Specific antibody with Glycoprotein G. J Clin Microbio 1985;22:641-4.

14 Ashley R, Militoni J, Lee F, Nahmias A, Corey L. Comparison of Western Blot (Immunoblot) and Glycoprotein G Specific Immunoblot Enzyme Assay for Detective, Antibodies to Herpes Simplex Virus Types 1 and 2 in Human Sero. J Clin Microbiol 1988;26:662-7.

15 Andrews EB, Tilson HH, Hurn BAL, Cordero JF. Acyclovir in pregnancy registry. $A m J$ Med 1988;85(suppl 2A): 123 .

16 Douglas JM, Critchlow C, Benedetti J, et al. A double blind study of oral acyclovir for suppression of recurrences of genital herpes simplex virus infections. N Engl J Med 1984;310:1551.

17 Straus SE, Takiff HE, Seidlin $M$. Suppression of frequently recurring genital herpes. A placebo controlled double blind trial of oral acyclovir. $N$ Engl J Med 1984;316:1545.

18 Mindel A, Weller IVD, Faherty A, et al. Prophylactic Oral Acyclovir in Recurrent Genital Herpes. Lancet 1984;2:57-9.

19 Halsos AM, Salo OP, Lassus A. Oral acyclovir suppression of recurrent genital herpes: a double blind, placebo controlled crossover study. Acta Dermato-Venereol suppl 1985;65:59.

20 Thin RN, Jeffries DJ, Taylor PK. Recurrent genital herpes suppressed by oral acyclovir: a multicentre double blind trial. $J$ Antimicrob Chemother 1985;16:219.

21 Stray-Pedersen B. Acyclovir in late pregnancy to prevent neonatal herpes simplex. Lancet 1990;336:756 (letter).

Accepted for publication 12 October 1990 